\title{
The Priority of Common Sense in Philosophy
}

MARTIN NUHLÍČEK

Comenius University in Bratislava, Slovak Republic

The aim of this paper is to explore the issue of priority of common sense in philosophy. It is divided into four parts. The first part discusses examples of common-sense beliefs and indicates their specific nature, especially compared to mere common beliefs. The second part explores in more detail the supposed positive epistemic status of common-sense beliefs and the role they play in delimiting plausible philosophical theories. The third part overviews a few attempts to formulate a legitimate argument, or justification, in favor of the positive epistemic status of common-sense beliefs, none of which, however, appears to be clearly successful. Finally, the fourth part addresses the central issue of priority of common sense. Two different types of priority are introduced, epistemic and methodological, and it is argued that only the latter applies to common-sense beliefs. If so, then common-sense beliefs are not to be conceived as cases of knowledge but as the clearest cases of what we believe is knowledge.

Keywords: Common Sense; metaphilosophy; philosophical method; philosophy of common-sense.

\section{Introduction}

There are thinkers who postulate the priority of common sense in (and over) philosophy. Typically, they claim that certain propositions or beliefs which are embedded in ordinary common sense also enjoy a specific status in philosophy. G. E. Moore called such beliefs "truisms" and included among them beliefs as "There are other people", "We have hands and bodies", "The Earth has existed for many years", etc. Such beliefs are held widely, almost universally. Indeed, we would hardly find a (normal) person to claim the contrary. But this is not all. According to some, common-sense beliefs also represent cases of knowl- 
edge. They are said to be the clearest and most elementary examples of what we know: we know that there are other people, we know that we have hands and bodies, we know that the Earth has existed for many years. This provides such beliefs with special epistemic status. The proponents of this view claim that common-sense beliefs form the basic data or background against which philosophical theories can be assessed. If any theory contradicts those beliefs, i.e. if a theory results in the exclusion of common-sense beliefs from knowledge, then it is a strong reason to reject the theory as implausible. In this sense, common sense regulates acceptable philosophical positions; in this sense, common sense takes priority over philosophy. This approach provides an easy solution to various traditional philosophical problems. An obvious example would be Cartesian skepticism, which, in this view, is reduced to a purely rhetorical practice, as it cannot really threaten our knowledge of the outside world.

However, as might be expected, many disagree. In their view, it is not permissible to solve complex philosophical problems simply by pointing to the widespread beliefs of ordinary people. Our common intuitions about knowledge are not skeptical, but therefore we cannot simply dismiss skepticism. We generally accept inductive reasonings, but that does not mean that such reasonings are therefore justified. From the traditional point of view, solutions to such problems require subtle philosophical arguments. Instead, basing solutions solely on the opinion of ordinary people seems unphilosophical and irrational. It would be rational only if we could present a convincing argument or evidence in favor of the positive epistemic status of common-sense beliefs. But the proponents of common sense themselves do not require such an argument or evidence; what is more, they doubt its possibility. Moore states: "We are all, I think, in this strange position that we do know many things, with regard to which, we know further that we must have had evidence for them, and yet we do not know how we know them, i.e. we do not know what the evidence was" (Moore 1959: 45). Despite that, the proponents of common sense insist that common-sense beliefs represent true knowledge and that philosophical theories must conform to them. Is there something wrong with them? Have they abandoned rationality? Or, on the contrary, have they discovered something important that traditional philosophy has long overlooked? Put in different words, should philosophy respect the priority of common sense?

The aim of this paper is to explore the issue of priority of common sense in philosophy. It is divided into four parts. The first part discusses examples of common-sense beliefs and indicates their specific nature, especially compared to mere common beliefs. The second part explores in more detail the supposed positive epistemic status of common-sense beliefs and the role they play in delimiting plausible philosophical theories. The third part overviews a few attempts to formulate a legitimate argument, or justification, in favor of the positive epistemic status of common-sense beliefs, none of which, however, appears 
to be clearly successful. Finally, the fourth part addresses the central issue of priority of common sense. Two different types of priority are introduced, epistemic and methodological, and it is argued that only the latter applies to common-sense beliefs. If so, then common-sense beliefs are not to be conceived as cases of knowledge but as the clearest cases of what we believe is knowledge.

\section{The Nature of Common-Sense Beliefs}

The proponents of common sense cite a number of different propositions that represent the beliefs of common sense. They include commonly held beliefs about the outside world, the past, the mental states of oneself and other people, as well as epistemic propositions stating knowledge of these things.

G. E. Moore gives the following examples of common-sense beliefs (see Moore 1953):

1. There are in the Universe an enormous numbers of material objects (e.g. our bodies, other people, animals, plants, stones, mountains, rivers, seas, planets, tables, chairs, etc.).

2. Human beings have minds inasmuch as we have a variety of mental states, including acts of consciousness. We see, hear, feel, remember, imagine, think, believe, desire, dislike, will, love and so on.

3. All material objects are located in space inasmuch as they are located at a distance from each other.

4. Mental acts are attached to-contained within-certain kinds of bodies (human bodies and perhaps those of the higher animals).

5. Mental acts are ontologically dependent upon bodies.

6. Most material objects have no acts of consciousness attached to them.

7. Material objects can and do exist when we are not conscious of them.

8. There was a time when no act of consciousness was attached to any material body.

9. All objects and acts of consciousness are in time.

10. We know 1.- 9. to be true.

Noah Lemos describes what he takes to be the main features of the common-sense tradition in philosophy (Lemos 2001: 204-206):

1. In answering certain philosophical questions, commonsensism holds that it is appropriate or reasonable to take as data certain ordinary, yet widely and deeply held, beliefs.

2. The commonsense philosopher takes these beliefs as data without having any proof for them.

3. The commonsense tradition is not committed to the view that our commonsense beliefs are indefeasible or immune to revision, but it does assign to our commonsense beliefs a great deal of "weight" or importance. 
There is no clear way to explicate the amount of "weight" placed on common-sense beliefs in philosophical discourse. But at least it is plausible to say that if a philosophical theory conflicts with one or another common-sense belief, the common-sense philosopher seeks to resolve the conflict in favor of common-sense beliefs. Therefore, "the commonsense philosopher seeks to be conservative in his revisions of his commonsense beliefs" (Lemos 2001: 206).

However, not every universally held belief is a common-sense belief. Or, to put it differently, common-sense beliefs do not gain their special philosophical status simply from the fact that they are universally held. Common-sense philosophers do not reject philosophical theories on the sole ground that they contradict some widely shared beliefs. It must be a common-sense belief that many know; if a theory suggests the opposite of such a proposition, it is a reason to reject that theory. But how are we to distinguish common-sense beliefs from universal beliefs that are not common-sense beliefs? Nicolas Rescher suggests making a distinction between common beliefs and common-sense beliefs. Whereas common beliefs are simply widely held beliefs, i.e. what everyone "knows", common-sense beliefs differ in their normative claim. They encompass items of information that everyone should know regarding the basic realities of human situation (Rescher 2005: 23). Thus, common beliefs are those which everyone accepts, while common-sense beliefs are those which every normal person should accept, were a question raised about them. In this sense, there is a connection between common sense and rationality. Mere common beliefs may also contain various mistakes and prejudices, as they did many times in history. Meanwhile, common-sense beliefs express what is ultimately reasonable to believe.

Now, what if someone denied common-sense beliefs? As Rescher points out, we would probably conclude that one did not first understand them. It is because there is "nothing sophisticated, complicated, or technical about common sense, and no special training or insight is needed for its realization. It relates to the sort of thing that anyone must realize who functions in the circumstances at issue" (Rescher 2005: 24). Another option is to just assume that the person in question is not mentally fit to grasp such propositions. Indeed, Rescher identifies "foolishness or idiocy" as one contrastive opposition to common sense (Rescher 2005: 26). Thomas Reid would also add to this group some philosophers who, with the help of philosophical arguments, allow themselves to arrive to opinions contrary to common sense. As he puts it, if someone were "to be reasoned out of the principles of common sense by metaphysical argument, we may call this metaphysical lunacy" (Reid 1823: 260). Of course, it does not mean that commonsense beliefs are utterly invariable or that they cannot be corrected or changed by philosophy. A critical examination may sometimes reveal discrepancies among common-sense beliefs and thus necessitate a revi- 
sion. However, in that case, we would be leaving the domain of common sense in a different direction. Intellectual performance which requires an amount of training and specific skills constitutes the other limit of common sense. It is known as expertise, which is the second contrasting opposition to common sense according to Rescher (Rescher 2005: 26).

Common sense itself does not need to be defined as a distinctive human faculty. Reid sometimes does refer to a faculty of common sense; however, it is not clear whether he considers it to be a sui generis faculty. In contrast, at one point he suggests that common sense may be "only another name for one branch or degree of reason" (Reid 1969: 567). Thus, common sense can be understood as the correct exercise of our general reasoning abilities; or simply as correct judgment. This assumption can be supported by Reid's very definition of common sense: "Common sense is that degree of judgment which is common to men with whom we can converse and transact business" (Reid 1969: 557). As it appears, common sense focuses on obvious truths that are neither complex knowledge nor require special expertise. They are just a matter of ordinary "correct judgment". Speaking more theoretically, common sense represents a kind of cognitive minimalism, i.e. awareness of things that are so evident that people with normal cognitive abilities cannot fail to realize their truth. Probably that is why the propositions of common sense are called truisms.

Particular truisms can be generalized into global epistemic claims, each of which includes a whole class of possible individual commonsense propositions. For instance, common-sense propositions such as "I have hands", "It is day", "There are other people", and the like, fall under a general epistemic claim "Those things do really exist which we distinctly perceive by our senses, and are what we perceive them to be." We may recognize Thomas Reid as the author of this claim (Reid 1969: 625). It was him who famously named a total of twelve such general claims, calling them principles of common sense. Those principles may be viewed as attempts to summarize the variety of common-sense judgments into a number of basic "axioms" which are thought to represent the most fundamental features of human cognition. It should be noted, however, that the discovery of the principles of common sense is the result of a specific philosophical endeavor, and their possession is therefore not itself part of common sense. One requires special philosophical expertise to be able to articulate such principles; hence, those principles constitute a philosophical reflection of common-sense beliefs. Clearly, that goes beyond the scope of ordinary common sense.

\section{The epistemic status of common-sense beliefs}

Common sense is often connected with the practical affairs of human life. For example, Rescher says: "Common sense is a realistic guide in matters of what to think and what to do" (Rescher 2005: 55). He states that common-sense beliefs are certain; however, not in the sense of ab- 
solute, anti-skeptical certainty but of practical, human-life certainty, which defines the standard of "being beyond reasonable doubt" (Rescher 2005: 29). Thus, common-sense propositions are not a matter of logical necessity. Nevertheless, they are strong presumptions that can hardly be denied: "To be sure, the claims of common sense do not have the backing of some sort of necessitation that guarantees their irrefragable certainty. But what they do have in their favor is a powerful presumption" (Rescher 2005: 57). Where does this presumption come from and what does it make of the epistemic status of such propositions?

To find an answer, we have to start with Reid's well-known characteristics of common-sense beliefs (as put in Rescher 2005: 35):

1. universality by way of being generally held;

2. commonality in reflecting the usage of all languages;

3. undeniability by way of being such that their contradictions are not merely false but absurd;

4. irresistibility so that even those who question them at the level of theory are compelled to accept them in conducting the practical affairs of life.

For the most part, it is the last characteristic, irresistibility, which plays the main role in determining the certainty of common-sense beliefs. In fact, we are not able to give up such beliefs as "There are other people". That makes them the fundamentals in our everyday reasoning, deciding, and acting. Any attempt to withhold common-sense beliefs, as is sometimes required by philosophical arguments, is therefore futile, because it is humanly impossible. As Lemos sums it up, it is impossible, first, psychologically, since those beliefs are irresistible. Second, it is impossible practically, as neglecting such beliefs would disrupt the course of everyday life. And third, it is supposed to be impossible also in a philosophical way, as those beliefs are referred to as inseparable parts of human nature (Lemos 2004: 73-74). Because common-sense beliefs are irresistible and impossible to give up, they are conceived to be self-evident. This means that their evidential status is not derived from an argument; that is, they neither require an argument nor do they admit one. No philosophical argument can make them more evident, just as no counter-argument can make them less evident. In general, the evidence of common-sense beliefs cannot possibly be altered on the basis of reasoning.

These features, I believe, lie at the heart of the presumed positive epistemic status of common-sense beliefs. Such beliefs are not subject to philosophical arguments, and yet, they basically constitute prime examples of what "evident" means. Because of that, they are supposed to enjoy a fairly high level of certainty. For what else could be labeled as certain, if not the most apparent self-evident beliefs? Therefore, common-sense beliefs are not taken as certain just because they are universally held. They are held to be certain because they are self-evident, and for the same reason they are also universally spread. What is more, common-sense 
philosophers typically understand the propositions of common sense as something we know. Not only do those propositions exhibit certainty in a psychological way, but it is also assumed that they form the epistemic basis of our knowledge. That basis itself does not have to be proved; on the contrary, it may serve as the source of proof for other propositions. Thus, the propositions of common sense are thought to represent the deepest foundations of knowledge, which can only be identified but not challenged. It may be analogous to other situations: we are certain that something is immoral, beautiful, etc., even if we cannot explain why.

The described epistemic status of common-sense beliefs allows its proponents to easily answer the problem of skepticism. They agree with the skeptic that certainty is a condition of knowledge. But they insist that a distinction must be made between reasonable certainty and the absolute certainty which the skeptic requires. The certainty of knowledge is the realistic certainty of life. To say that something is certain is to say that it is as certain as anything of that kind can be. Commonsense beliefs are conceived as prototypes of such certainty. So, from the common-sense point of view, the skeptic demands certainty that is realistically unattainable, and, on the other hand, she tries to challenge beliefs that are in fact unquestionable. Therefore, the skeptic can be answered as follows: when we have taken all the steps to achieve reasonable certainty, then we have knowledge. If the skeptic is not satisfied with this, she places unreasonably high criteria on knowledge and demands evidence that is practically impossible to provide. In the eyes of common-sense philosophers, since skepticism proves itself as unreasonable, we can safely ignore it. Some have gone even further, and, from the position of common sense, they have tried to respond directly to the skeptical challenge. A shining example was G. E. Moore, who presented his "proof of an external world" by drawing attention to the belief that he had two hands (see Moore 1993). Nevertheless, he only provoked confusion, probably because he mixed two different views. From one point of view, his answer sounds quite convincing because he presents a simple common-sense belief; but from the other point of view, his common-sense answer does not provide the expected level of expert elaboration, which gives the impression of insufficiency. Hence, for the common-sense philosopher, it seems more appropriate to point out a conflict between skeptical requirements and common sense than to attempt to respond directly to the skeptic.

Common sense sets limits not only to skepticism but also to any philosophical theory whose consequences would contradict common-sense beliefs. The proponents of common sense typically argue as follows:

1. Proposition $\mathrm{P}$ is a common-sense proposition which everyone knows.

2. Theory $\mathrm{T}$ implies that no one knows $\mathrm{P}$.

3. Therefore, theory $\mathrm{T}$ is false.

In this argument, we can see that the propositions of common sense are indeed attributed a high epistemic status. Contradiction with such 
propositions alone is considered sufficient to reject the whole theory. It is precisely in this sense that common-sense beliefs serve as "hard data" to which philosophical theories have to conform.

The approach in which common-sense beliefs take epistemological precedence over philosophical theories is expressed in the works of several authors sympathizing with the common-sense view. For instance, we find Roderick Chisholm saying (Chisholm 1982: 113):

It is characteristic of "commonsensism," as an alternative philosophical tradition, to assume that we do know, pretty much, those things we think we know, and then having identified this knowledge, to trace it back to its sources and formulate criteria that will set it off from those things we do not know.

Thomas Reid suggests that common sense creates the ultimate criterion for the acceptability of different philosophical positions (Reid 1823: 17):

A traveller of good judgment may mistake his way, and be unawares led into a wrong track; and while the road is fair before him, he may go on without suspicion and be followed by others but, when it ends in a coal pit, it requires no great judgments to know he hath gone wrong, nor perhaps to find out what misled him.

Elsewhere, Moore writes (Moore 1922: 163):

There is no reason why we should not, in this respect, make our philosophical opinions agree with what we necessarily believe at other times. There is no reason why I should not confidently assert that I do really know some external facts, although I cannot prove the assertion except by simply assuming that I do. I am, in fact, as certain of this as of anything; and as reasonably certain of it.

The epistemological function of common-sense beliefs is consistent with what Chisholm describes as particularism. This view argues that the study of knowledge begins with cases that are considered to be clear knowledge, and only according to them do we try to formulate criteria for knowledge (Chisholm 1973: 14-15). Of course, one may ask, how can we recognize that our initial "knowledge" is correct and unaffected by error? We cannot, the particularists reply. But they point out that there is no other reasonable way to conduct the study of human knowledge. We can only start with things we know and then try to examine and improve them.

Let us quote Chisholm again (Chisholm 1977: 16):

We presuppose, first, that there is something that we know and we adopt the working hypothesis that what we know is pretty much that which on reflection we think we know. This may seem like the wrong place to start. But where else could we start?

\section{Justification of common-sense beliefs}

Common-sense beliefs are irresistible. They represent the highest level of practical certainty a belief can possibly acquire. But the question of their psychological irresistibility must be separated from the question of their 
epistemic legitimacy. In a broader sense, we have to determine whether the psychological specificity of some beliefs justifies the special epistemic status they allegedly possess. Or, as Christopher Hookway puts it: "We must decide whether appeal to such 'common-sense' certainties embodies a response to fundamental epistemological issues or is simply an attempt to ignore them" (Hookway 1990: 397). Speaking about knowledge claims, they are generally associated with the possibility of being exposed to critical challenges. If someone answered the question of how she knows something, that she only insists she knows it, it would seem irrational. This is why some recent epistemologists have complained that G. E. Moore's anti-skeptical common-sense insistence that he knows there is a hand in front of him is more a stubborn refusal to take skepticism seriously than a philosophically sensitive response to it (Hookway 1990: 401). Therefore, according to Hookway, the philosophy of common sense does not end with simply naming certain common-sense beliefs. In addition, "a common-sense philosophy must explain why it is legitimate to trust these certainties. This is the fundamental difficulty facing a philosophical appeal to common-sense" (Hookway 1990: 399).

A philosophical appeal to common sense without justifying its contributions would be, no doubt, unsatisfactory. Immanuel Kant develops his well-known critique of common-sense philosophy exactly along the same lines. He writes (Kant 1950: 7):

It is indeed a great gift of God to possess right or (as they now call it) plain common sense. But this common sense must be shown in action by wellconsidered and reasonable thoughts and words, not by appealing to it as an oracle when no rational justification for one's position can be advanced.

As we can see, Kant takes appealing to common sense as opposed to rational justification. In his view, reliance on common sense cannot be philosophically legitimate unless it is substantiated by justifying reasons. Although Kant's critical view of common sense may not be widely shared today, his assumption has been preserved; namely, that if common sense is to serve philosophical purposes, it must be appropriately justified. This assumption is also present in current accounts of common-sense beliefs. For example, Noah Lemos lists two essential points regarding the possibility of common-sense knowledge (Lemos 2004: 14-15):

First, in order to have common-sense knowledge, one needs a general criterion that tells us that beliefs of such common-sense sort represent knowledge.

Second, to fulfil the criterion, an argument—one free from epistemic circularity-is crucial for having the sort of knowledge that the common-sense philosopher claims.

Thus, the attempt to rationally justify common-sense beliefs amounts to searching for a rational argument that would support their positive epistemic status. It is crucial that the argument be "free from epistemic circularity", i.e. it must not presuppose the epistemic status of the beliefs whose epistemic status is to be proved. To presuppose something 
which is just to be proved would be, of course, a fallacy of reasoning. So, can such an argument be effectively constructed? Let us review a few notable attempts.

William Alston, for example, admits that justificatory arguments in support of our cognitive abilities are epistemically circular, but at the same time he points out that no such non-circular arguments are available. Hence, we have to accept epistemic circularity, which, however, might not be irrational. Alston favors an approach which appeals to the "practical rationality" of our ways of forming beliefs. He argues that many of our belief-forming ways are firmly established. It does not seem to be in our power to avoid forming beliefs in the established ways and substitute them with entirely different ways. At least, it would probably be very difficult to do so. Moreover, the same problem of epistemic circularity that beset our practices would also confront these new alternatives. Given these facts, Alston concludes that it is "practically rational" for us to continue engaging in our established ways of forming beliefs (Alston 1996: 271).

Alston's argument may be viewed as pragmatic, provided that the only alternative is to admit our beliefs as widely unjustified. But does it offer a plausible solution to the problem of justifying common-sense beliefs? One might object that the method described could also allow justification for such things as crystal ball gazing. Of course, such objection would be unfair, as crystal ball gazing is certainly not an established way of how people form beliefs. Nevertheless, Alston's view invites perhaps a little more circularity than he intended to, since his very argument appears to be epistemically circular. His conclusion about which ways of forming beliefs we should continue to engage in is derived from a premise describing what ways of forming beliefs we actually engage in. In the words of Ernest Sosa: "If we push reflection far enough with regard to why we should accept the premises of this argument, don't we find ourselves appealing precisely to its conclusion?" (Sosa 1996: 315). If it is true that Alston's argument is circular, in a way it only emphasizes the need to find an argument that avoids circularity.

Let us proceed to Sosa's own view. Like Alston, he thinks that epistemic circularity in justifying our fundamental beliefs is inescapable, but he too suggests that it does not preclude those beliefs from being justified and, hence, rational. However, Sosa develops his argument from a more general position. He considers the totality of our beliefforming ways, which he refers to as $\mathrm{W}$. When we take $\mathrm{W}$, he says, then by using $\mathrm{W}$ we can know that $\mathrm{W}$ is reliable. The fact is that this conclusion is formed by the use of our best intellectual procedures. Although we have not avoided epistemic circularity, it is not at all easy to pinpoint what has been omitted or done wrong in this argument. Sosa therefore concludes that it is permissible to justify our belief-forming processes in a circular way, as we have no other overall way to do so (Sosa 1996: 318). This resembles Alston's argument on a larger scale: 
we have no other totality of belief-forming ways than $\mathrm{W}$, so it is permissible to prove with $\mathrm{W}$ that $\mathrm{W}$ is rational. But if there is a genuine similarity with Alston, then Sosa's argument is also circular itself.

Alston and Sosa both argue that from a practical point of view, we have no other option than to rely on the belief-forming processes that we naturally possess. As already pointed out, it is to be conceived as a pragmatic response that primarily seeks to avoid the skeptical alternative that our beliefs generally lack justification. Sometimes it is argued that any reasons that have not yet been challenged can be safely used for belief-justification even if it is circular. This view is based on the principle of "innocence" of reasons, unless proven otherwise. For instance, Michael Bergmann makes a difference between "malignant" and "benign" epistemic circularity. The former kind of epistemic circularity arises in a questioned source context, as he calls it, while the latter arises in an unquestioned source context. And while epistemic circularity in a questioned source context is obviously "bad" (as he calls it again), epistemic circularity in an unquestioned source context is not necessarily mistaken. In a questioned source context, we cannot use the source to verify its own reliability-precisely because it is questioned. We would need an independent argument for that. But if we are just reconstructing the reasons why we believe in the reliability of a source without questioning it, we do not need an independent argument (Bergmann 2004: 717-721). This allows the justification of beliefs, including common-sense beliefs, by any other beliefs and sources which are presumed to be justified, provided that they have not been challenged so far. Thus, Moore can be justified in the belief that there is a hand in front of him just on the basis of his plain sight, provided that his sight has not been questioned. And similarly, the reliability of his sight can be justified by the fact that it correctly informs him about external things such as hands - again, provided that this capability has not been questioned.

But the crucial question is not whether we are relying on circularity in justification, but whether circular justification is epistemically legitimate. Those are two independent questions. Even if the answer to the first one is affirmative, it does not necessarily imply that the answer to the second one would be affirmative as well. As for the second question, it is certainly true that to grant epistemic circularity is to grant a method which is generally conceived to be fallacious. However, there appear some options how to handle the problem of epistemically circular justification. One could suggest, for instance, that circular justification should be allowed where no non-circular justification is available. When there is no non-circular justification to the belief that "there is a hand in front of me", a circular argument can be used, such as: "There is a hand in front of me, which is justified by the reliability of my visual perception, which, in turn, is justified because it correctly informs me about external things, such as hands, being in front of me." 
Even if we overlook the fact that such arguments look unsatisfactory at first glance, there is a deeper problem. If we allow circular justification in some cases, how do we prevent circular reasoning in all cases? Based on what criterion should we distinguish that we admit the circular justification of perception or memory but not, for example, of telepathy? It is not at all easy to answer such objections.

The fact is that most authors deny the possibility of epistemic circularity as a rational method of justification. Richard Fumerton is one of the most radical ones, who, to prove the point, compares circular justification of belief-forming processes to the justification of astrology (Fumerton 1995: 177):

If a philosopher starts wondering about the reliability of astrological inference, the philosopher will not allow the astrologer to read in the stars the reliability of astrology. Even if astrological inferences happen to be reliable, the astrologer is missing the point of a philosophical inquiry into the justifiability of astrological inference if the inquiry is answered using the techniques of astrology.

In his particularly dramatic way, he concludes that epistemic circularity is completely inadmissible (Fumerton 1995: 177):

You cannot use perception to justify the reliability of perception! You cannot use memory to justify the reliability of memory! You cannot use induction to justify the reliability of induction! Such attempts to respond to the skeptic's concerns involve blatant, indeed pathetic, circularity.

Fumerton apparently expects some independent, i.e. non-circular, argument in favor of the credibility of our cognitive sources. His expectation is probably derived from the fact that we usually require independent justifications of local beliefs. For example, a particular memory might be quite independently justified with photographs, written records, memories of others, etc. But when it comes to the general justification of our belief-forming methods as such (e.g. memory as such), it appears to be considerably difficult, if not impossible.

Thus, moving back to common-sense beliefs, it seems that there is no unproblematic way of justifying them with an argument free from epistemic circularity. This puts us in a position where we must look for some way to epistemically support common-sense beliefs other than on the basis of an independent argument. In the words of Noah Lemos: "If a philosophical curiosity about the reliability of our faculties could only be satisfied by an argument free of epistemic circularity, then it would seem to be a mark of philosophical wisdom to accept the fact that that cannot be done" (Lemos 2004: 51).

\section{The priority of common-sense beliefs}

What attitude should one take to the question of the legitimacy of common-sense beliefs? As we have seen, attempts to support it with an argument free from epistemic circularity seem problematic. One has only a few options how to deal with it. First, one can admit epistemic 
circularity and insist that our beliefs are legitimately justified in a circular way. Some authors adhere to this position, yet it is not at all clear if the controversy which it contains can be resolved. Second, one can argue that there is no satisfactory way of supporting our beliefs and thus conclude that we do not know the things we believe to know. This is the position of skepticism that has notoriously little philosophical appeal, mainly because it refuses human knowledge instead of seeking for its explanation. There is also a third option. One can claim that some of our beliefs have a special epistemic status that allows them being justified even without a supporting argument. This approach is known as foundationalist, since it treats some beliefs as foundational, i.e. as epistemological "axioms" whose legitimacy is somehow based in themselves and is not to be proved by an argument. Such a view makes it possible to circumvent the issue of searching for a non-circular argument, and, at the same time, it is conceived as not inviting skepticism.

Common-sense philosophers typically consider common-sense beliefs to be foundational. Thomas Reid postulates them as ultimate sources which may provide justification for other beliefs but do not need such support themselves. He insists that justification "must stop only when we come to propositions which support all that are built upon them, but are supported by none themselves—-that is, to self-evident propositions" (Reid 1969: 596).

Such propositions neither require nor admit of proof; their epistemic authority is independent and, in fact, superior to any argument that could be formulated in favor of them (Reid 1969: 116):

[It] is not by any train of reasoning or argumentation that we come to be convinced of the existence of what we perceive; we ask no argument for the existence of the object, but that we perceive it; perception commands our belief upon its own authority, and disdains to rest its authority upon any reasoning whatsoever.

According to Reid, common-sense beliefs are self-evident and thus give us immediate knowledge. They are subject to no proof or reasoning, and yet they are justified. As he puts it, they somehow bear "the light of truth" in themselves: "[t]here is no searching for evidence; no weighing of arguments; the proposition is not deduced or inferred from another; it has the light of truth in itself, and has no occasion to borrow it from another" (Reid 1969: 593).

But Reid's view can only hold if we presuppose that our cognitive faculties generally work properly. Otherwise-if our faculties were thought of as possibly prone to error-their contributions could not be safely regarded as knowledge. And indeed, Reid states as a general principle that "the natural faculties, by which we distinguish truth from error, are not fallacious" (Reid 1969: 630). Now, the crucial question is: how do we know this principle to be true?

Reid holds that it is a first principle, simply known to be true. By holding that proposition to be a first principle, he suggests that the general statement about the reliability of our natural faculties is im- 
mediately evident. It is neither inferred from any other proposition nor dependent on any argument. For Reid, such conviction would probably be the testimony of some natural faculty itself_-or, as Lemos somewhat uncharitably puts it, "some faculty 'vouching' for itself" (Lemos 2004: 71). In any case, it is regarded as a foundational principle which, immediately known, provides epistemic justification for other, non-foundational propositions. It is in this way that Reid rejects the view that the only epistemically satisfactory way to know that our faculties are reliable is via a non-circular argument.

Moreover, he offers a variety of philosophical as well as practical reasons which imply that without such a principle, a non-skeptical epistemology could not be constructed. From one traditional point of view, epistemology struggles to combine three different claims:

(1) We know things.

(2) We can know things only if our cognitive faculties are reliable.

(3) We do not know if our cognitive faculties are reliable.

The skeptic accepts (2) and (3) and derives from them that (1) does not hold. Anti-skeptical authors, on the other hand, take (1) as a premise and rather attempt to modify (2) or (3) accordingly. What about common-sense philosophers? They claim that to give up (1) would be philosophically and practically unreasonable (or even absurd) and to give up (2) would be irrational. Therefore, they modify (3) to its exact opposite: We know that our cognitive faculties are reliable. Combined with (2), this allows them to logically support the common-sense conclusion (1).

In the previous section, we could see Alston and Sosa trying to prove the opposite of (3) with arguments which were, nevertheless, circular. A wholly different strategy was proposed in Sosa's later work, where he introduced a distinction between animal knowledge and reflective knowledge. In its simplest form, animal knowledge involves just knowing a thing, whereas reflective knowledge requires also knowing how and why we know that thing (see Sosa 2007: 24). Since for most ordinary purposes it is quite sufficient to exhibit animal knowledge, we can assert (1) without paying attention to (2) and (3). Thus, Sosa's approach may be understood as an attempt to "dissolve" the problem of the three claims for ordinary knowledge. But this is not to be confused with the position of common-sense philosophy. Its proponents typically acknowledge the importance of explaining our knowledge, i.e. of explaining the relations between the three claims. As already mentioned, in following the main aim of defending (1), they turn (3) to its opposite. They believe such move is legitimate, for as they see it, the general reliability of our faculties is a foundational truth.

From a methodological point of view, it is possible to place Reid (and other proponents of common-sense philosophy) in the before-mentioned position of particularism (see section 2). According to it, any relevant study of knowledge can be effectively initiated in no other way than by assuming that our cognitive faculties work (roughly) properly. There is literally no alternative to initially trusting at least some of our facul- 
ties. But from a logical point of view, to hold that some propositions are foundational in character does not amount to a guarantee of them being true. For instance, a clear deliverance of the senses would certainly be referred to as foundational knowledge. However, since it is contingent, it is still logically compatible with the possibility of error, however slight. It is this feature that prevents many authors from accepting foundational beliefs as unproblematic knowledge.

As it appears, the debate on common-sense beliefs is twofold; first, common-sense beliefs are treated as starting points of epistemic scrutiny, and second, they are attributed with a peculiar epistemic status of foundational knowledge. These differences are well captured in John Greco's distinction between two kinds of priority held by common-sense beliefs:

In brief, common sense beliefs enjoy an epistemological priority in that they constitute a foundation for knowledge: such beliefs enjoy the kind of evidential status required for knowledge, even without being grounded in further evidence themselves. Common sense beliefs enjoy a methodological priority in that they constrain philosophical theory: such beliefs serve as pre-theoretical commitments that philosophical theories ought to respect, at least in the absence of good reasons for rejecting them. (Greco 2014: 142)

Let us have a look at both kinds of priority in more detail.

Methodological priority, as already indicated, concerns commonsense beliefs as the starting points of philosophical scrutiny of human knowledge. It suggests that any philosophical theory has to respect common-sense beliefs in the sense that it should not arbitrarily contradict them or lead to a consequence that contradicts them. However, there is no absolute bar to violating common sense: a theorist may speak against common sense, but if she does, she has to provide very good reasons to do so. Thus, the methodological priority may be thought of as prima facie: one's theory might end by violating common sense, but it should not start off that way. The contrary approach, i.e. disregarding the principles of common sense and postulating philosophical constructions instead, would probably be not only ineffective in explaining real human knowledge but, as Reid famously points out, also potentially destructive for the philosophical effort itself: "Such principles are older, and of more authority, than Philosophy: she rests upon them as her basis, not they upon her. If she could overturn them, she must be buried in their ruins" (Reid 1823: 14).

Epistemic priority, on the other hand, is the thesis that commonsense beliefs are examples of foundational knowledge and are known directly even in the absence of supporting arguments. One interpretation suggests that this view is based on the principle that our beliefs should be treated as "innocent until proven guilty". But according to Greco, such principle explains methodological priority rather than epistemic priority (Greco 2014: 147-148). So how could we explain the alleged epistemic priority of common-sense beliefs? Three possible options come into consideration. First, a special epistemic status of 
common-sense beliefs may be supported by an independent argument. As demonstrated before, such attempts end in epistemic circularity. Second, we can point to the irresistibility of common-sense beliefs and our incapability of giving them up without feelings of discomfort or absurdity. Especially Reid often resorts to this type of defense, but, as already stated, it is more a defense of methodological than of epistemic priority. To claim that we cannot easily abandon certain beliefs is to claim their strategic position in our cognitive systems, but not yet that they accurately represent the corresponding states of affairs. And third, common-sense beliefs may be declared as epistemically prior by definition: if a belief is identified as common-sense belief, it is assumed to have a positive epistemic status. This understanding, I believe, is the closest to the foundationalism of common-sense philosophy. However, it entirely begs the question of why those beliefs enjoy such a special epistemic status. This is not just philosophically unsatisfactory, but some may even see it as a dogmatic insistence on popular beliefs based on folk psychology.

We can see that each of the three ways to justify the epistemic priority of common-sense beliefs seems controversial. Hence, there appears to be no unproblematic sense in which common-sense beliefs could be thought of as having the epistemic kind of priority. This is not to say that they do not have it or that they never amount to knowledge. The point is that it is something that has yet to be proven. History teaches us this as well, since many widely held beliefs in the past have turned out to be wrong. Therefore, simply claiming that present widely held beliefs are not wrong appears rather philosophically naïve. As a result, common-sense foundationalism is far from being universally accepted (to put it mildly), as it raises serious suspicions of circularity or dogmatism.

A supporting reason undermining the idea of epistemic priority of common-sense beliefs may also be found in some recent findings in the field of philosophy of mind. Folk psychology, i.e. common-sense explanations of various psychological phenomena, turn out to be wildly mistaken in many different respects. For instance, Paul Churchland compiles a whole list of issues that folk psychology cannot explain or even fails to address: the nature of mental illness, the faculty of creative imagination, the ground of intelligence, the psychical functions of sleep, and many more (see Churchland 1981: 73 ff.). According to eliminativists, as they are labelled, the main problem is that folk psychology vocabulary is, in its central categories, massively wrong and therefore should be abandoned in favor of a more correct "scientific image", describing those issues with more refined and accurate categories. As Churchland concisely puts it, "our commonsense conception of psychological phenomena constitutes a radically false theory, a theory so fundamentally defective that both the principles and the ontology of that theory will eventually be displaced"-by science (Churchland 1981: 67). If we draw an analogy between the philosophy of mind and 
epistemology, we may come to a suspicion that similar problems may affect at least some of our common-sense beliefs, too. Apart from the fact that they can be factually incorrect, the very categories by which they express and describe the world around us may not be adequate or relevant. Again, this puts one in a position where one should be very cautious with the notion of epistemic priority of common-sense beliefs. Not only their factual, but also their semantic aspects seem to be something yet to be explored.

\section{Conclusion}

As far as our inquiry indicates, common-sense beliefs do enjoy methodological priority, but they do not enjoy epistemic priority. We have found no convincing way to rationally (i.e. non-dogmatically and noncircularly) account for the alleged positive epistemic status of commonsense beliefs. It is possible that the appearance of epistemic priority is caused by psychological features (such as irresistibility) which are related rather to the methodological priority of those beliefs-but for now, this is only a speculation. In any case, if common-sense beliefs do not have epistemic priority, they do not constitute knowledge; or, to be more precise, they do not necessarily constitute knowledge. This consequence is supported by the fact that according to most accounts of knowledge, one necessary condition of knowledge is truth. But since common-sense beliefs are contingent in nature and thus not entirely immune to revision-as the proponents of common sense themselves admit, on occasions the inadequacy of a common-sense belief can be revealed and replaced by a different belief-they cannot be labelled as true by definition. Otherwise, it would have to be the case that in some periods of time, we know something that is not true. This is an $a d a b$ surdum outcome which shows that common-sense beliefs should not be automatically treated as knowledge. To be clear, it is not to be denied that some common-sense beliefs may actually pose knowledge. But this has to be assessed individually and not just generally declared simply because many people find such beliefs compelling. Good candidates for knowledge will probably be the most ingrained common-sense beliefs, such as that other people exist. But a complex analysis is not my intention here.

As for the methodological priority, we have found no reasons why it should not hold. Some beliefs seem to be more psychologically significant than others, and common-sense beliefs may be considered to be the most significant ones in this respect. Therefore, special attention should be paid to them in theoretical investigations. As a basic norm, theories should not openly contradict such beliefs; they should not imply, for example, that there are no material objects, or that our vision generally deceives us. And if they do, they are expected to explain it adequately and also to show what notable theoretical advantages do we accomplish in exchange. In some domains, a change of the initial 
common-sense view already allowed us to better understand and predict different phenomena. The atomic structure of things, the Earth's motions, the viral causes of infections, etc.-all of these theories are not commonsensical in the first place, but science widely proved their usefulness. As previously mentioned, common-sense beliefs are generally revisable, since they are contingent. But any such revision has to be properly motivated and justified, otherwise it may run into a barrier of psychological unacceptability. Thus, theories have to either respect common-sense beliefs, or, when they explain them away, they must do so with enough detail, care, and conviction. For these reasons, common-sense beliefs are thought to be methodologically prior, both in science and philosophy.

To sum up, in this paper we have shown, first, that common-sense beliefs are to be distinguished from mere common beliefs in that they also possess a normative appeal prescribing what (normal) people should believe. Second, that common-sense beliefs are by some thought of as knowledge which serve for philosophical theories as ultimate data that should not be contradicted. Third, that the most critical question concerns the epistemic justification of common-sense beliefs, but providing a satisfactory answer to this question has proved problematic. And fourth, that the priority of common sense in (and over) philosophy seems to be rooted in the distinctive psychological features of commonsense beliefs and thus appears methodological rather than epistemic. If so, common-sense beliefs are not to be conceived as unconditional knowledge, since the real epistemic status of each such belief has to be determined by investigation. But they may be thought of as the starting points of every inquiry, including the one concerning human knowledge. In this sense, they represent the clearest cases of what we believe is knowledge, although further philosophical scrutiny may reveal some of those beliefs to be inaccurate.*

\section{References}

Alston, W. P. 1996. “A 'Doxastic Practice’ Approach to Epistemology.” In P. K. Moser. (ed.). Empirical Knowledge. Lanham: Rowman and Littlefield: 269-301.

Bergmann, M. 2004. "Epistemic Circularity: Malignant and Benign.” Philosophy and Phenomenological Research 69 (3): 709-727.

Chisholm, R. M. 1973. The Problem of the Criterion. Milwaukee: Marquette University Press.

Chisholm, R. M. 1977. Theory of Knowledge. 2nd edition. Englewood Cliffs: Prentice Hall.

Chisholm, R. M. 1982. The Foundations of Knowledge. Minneapolis: The University of Minnesota Press.

* This work was supported by the Scientific Grant Agency of the Ministry of Education, Science, Research and Sport of the Slovak Republic and the Slovak Academy of Sciences, under the number VEGA 1/0258/2019-Realism and AntiRealism in Contemporary Philosophy of Science. 
Churchland, P. M. 1981. "Materialism and the Propositional Attitudes." The Journal of Philosophy 78 (2): 67-90.

Fumerton, R. 1995. Metaepistemology and Skepticism. Lanham: Rowman and Littlefield.

Greco, J. 2014. "Common Sense in Thomas Reid." Canadian Journal of Philosophy 41 (Sup. 1): 142-155.

Hookway, C. 1990. "Common-Sensism and Rational Self-Control." Noûs 24 (3): 397-411.

Kant, I. 1950. Prolegomena to Any Future Metaphysics. Indianapolis: Bobbs-Merrill.

Lemos, N. 2001. "Commonsensism in Ethics and Epistemology." In M. Steup (ed.). Knowledge, Truth, and Duty. Essays on Epistemic Justification, Responsibility, and Virtue. Oxford: Oxford University Press: 204-218.

Lemos, N. 2004. Common Sense. A Contemporary Defense. Cambridge: Cambridge University Press.

Moore, G. E. 1922. "Hume's Philosophy.” In Philosophical Studies. London: Routledge and Kegan Paul: 147-167.

Moore, G. E. 1953. "What Is Philosophy?" In Some Main Problems of Philosophy. London: George Allen and Unwin: 1-27.

Moore, G. E. 1959. “A Defence of Common Sense.” In Philosophical Papers. London: George Allen and Unwin: 32-59.

Moore, G. E. 1993. "Proof of an External World." In Selected Writings. Ed. T. Baldwin. London: Routledge: 147-170.

Reid, Thomas. 1823. An Inquiry into the Human Mind on the Principles of Common Sense. London: T. Tegg.

Reid, Thomas. 1969. Essays on the Intellectual Powers of Man. Cambridge: MIT Press.

Rescher, N. 2005. Common-Sense: A New Look at an Old Philosophical Tradition. Milwaukee: Marquette University Press.

Sosa, E. 1996. "Philosophical Scepticism and Epistemic Circularity." In P. K. Moser (ed.). Empirical Knowledge. Lanham: Rowman and Littlefield: 303-329.

Sosa, E. 2007. A Virtue Epistemology. Apt Belief and Reflective Knowledge. Volume I. Oxford: Clarendon Press. 
